\title{
EDITORIAL
}

\section{Consent: A Luta Continua}

Hard on the heels of the successful $21^{\text {st }}$ ISfTeH International Conference in Casablanca in December, the $22^{\text {nd }}$ International Conference was held in combination with the $23^{\text {rd }}$ annual meeting of the Finnish Society for Telemedicine and eHealth in March. A conference with a difference, on a ferry sailing from Helsinki to Stockholm and back again across a frozen Baltic Sea. Another success. During a site visit to a primary care facility in Stockholm a new phone app under trial was demonstrated. The app enables patients to book a videoconference consultation with the facility's physician or nurse and the phone is used as the videoconference device. Interesting, yes, but more interesting was the response of the doctor and nurse to a question about consent for the teleconsultation - for which, by the way, the patient pays a full fee. They looked bemused. The question was repeated to ensure that it had been understood. They shook their heads. No consent is requested or gained. Consent is implied.

As telemedicine integrates into everyday medical practice, are the days of requiring telemedicine specific consent over? Do radiologists get telemedicine specific consent for routine digital radiography? But new methods of communication and their use for telemedicine bring new issues. Take 'Selfie' telemedicine for example. Patients take and submit photos or videos of themselves. Although little known, this is a fast growing field for skin self-examination, postoperative wound assessment following day surgery, and direct to consumer services such as teledermatology. 'Selfie' telemedicine comes in different flavours; i) physician directed services in which the physician asks the patient to take and submit photographs and information, as for example in wound assessment, ii) patient initiated telemedicine with their physician, iii) patient initiated telemedicine with a physician who does not know them, iv) direct to consumer services, where patients interact with someone who may or may not be a physician, and v) insurers or health service providers offering a physician on call for telemedicine who may or may not know you.
The specific legal, ethical, and security issues differ, as well as responsibilities of the initiator and receiver.

Consent implies understanding what is being consented to. Again, several issues arise. Do we understand how data are being transmitted, stored, and with whom they are being shared when we consent? What about language? While consent should ideally be obtained in one's mother tongue, what happens if language has not kept pace with technology and there are no words for what has to be explained and understood for valid informed consent to be obtained. ${ }^{1}$

Food for thought.

On a different note. We bid farewell to Malina Jordanova, one of the founding editors of the Journal. Malina was the editor, with Frank Lievens, of the precursor to JISfTeH, "Global Telemedicine and eHealth Updates: Knowledge Resources" the peer reviewed journal of papers from the annual Med-e-Tel conference in Luxembourg. One of the goals of JISfTeH was to incorporate Global Telemedicine and eHealth Updates and this we did last year. Sadly, Med-e-Tel has taken a sabbatical in 2018. To maintain continuity we will, over the coming months, link all of the past Mede-Tel papers to JISfTeH. We send our thanks to Malina for her diligent and unerring contributions and wish her well.

In this edition of the Journal, we also present a Special Theme on Disaster eHealth. As the name implies, this is simply the use of eHealth (Information and Communication Technologies (ICT) for health) ${ }^{2}$ for the purposes of responding to, recovering from, or preparing for disasters. Disasters are typically classified as either natural disasters (caused directly or indirectly by natural hazards) or technological / man-made disasters (caused directly or indirectly by human action or inaction). Some literature points to the frequency, severity, and cost of disasters increasing. Addressing disasters through disaster / emergency response plans prepared by local, national, and even global agencies is now common practice. 
Historically the use of telemedicine in response to disaster is nothing new, with perhaps the first reports emerging in the 1980s in response to earthquakes in Mexico City and Armenia. ${ }^{3}$ However it is telling that guiding documents from global agencies do not directly acknowledge or promote the use, or contribution, of ehealth. ${ }^{4,5}$ It is also telling that most applications have been of telemedicine during the immediate post-disaster response phase of the disaster management cycle, not throughout.

Recently a small group of individuals from Universities across the globe has begun an initiative termed the Disaster eHealth Community of Interest (DeCOI). Through seed funding made available from the Royal Society of New Zealand, the Auckland University of Technology (AUT), together with the University of Agder, Norway and the University of Nebraska at Omaha, USA, have supported this initiative through group and conference workshops. Members from other Universities have joined the group, including the University of Grenoble, France, and the University of Calgary, Canada.

What is their goal? At this time the full spectrum of potential contributions of eHealth is uncertain. Members of DeCOI (Norris, Parry, Gonzalez, Khazanchi, Dugdale, Scott, and others) are examining what the depth and breadth of DeH might be, and how it relates to other established areas of activity, such as Disaster Medicine, and Disaster Management. Some questions they are striving to answer are; will eHealth help in a comprehensive manner, if so how, and what challenges and requirements stand in the way?

As the cliché goes, it is not a matter of if a disaster will occur, but rather when (and where) the next disaster will occur. DeCOI is stimulating a dialogue. We encourage you to read about, embrace, and even contribute to, this new field of research - Disaster eHealth.

And what of consent during a disaster?

\section{Maurice Mars \\ Richard E Scott}

\section{References}

1. Jack CL, Singh Y, Hlombe B, Mars M. Language, cultural brokerage and informed consent - will technological terms impede telemedicine use? $S$ Afr J Bioeth Law 2014;7:14-18.

2. World Health Organization. eHealth at WHO. Available at: http://www.who.int/ehealth/en/, accessed 28 March 2018.

3. Doarn CR, Merrell RC. Telemedicine and ehealth in disaster response. Telemed J E Health 2014;20(7):605-606. doi: $10.1089 /$ tmj.2014.9983.

4. The Sendai Framework for Disaster Risk Reduction 2015-2030 (Sendai Framework). Available at: https://www.unisdr.org/we/inform/publications/4 3291, accessed 28 March 2018.

5. UNISDR's Strategic Framework 2016-2021. Available at: http://www.unisdr.org/we/inform/publications/51 557, accessed 28 March 2018. 